\title{
One day is not as good as another...at least not across the entire territory of Italy: an analysis of the differences in the daily distribution of births across Italian macro-regions, 1999-2016
}

\author{
Marco Breschi, Gabriele Ruiu* (iD and Giovanna Gonano
}

\author{
* Correspondence: gabrieleruiu@ \\ gmail.com \\ Department of Economics and \\ Business, University of Sassari, Via \\ Muroni, 25, 07100 Sassari, Italy
}

\begin{abstract}
The concentration of births on working days compared to a relative lack of events at weekends or during public holidays has been interpreted in literature as evidence of an excessive appeal to elective delivery. The World Health Organization has repeatedly expressed concerns about the abuse of this practice. We investigate the daily distribution of births in Italy in the period 1999-2016 to answer the following question: In addition to the weekend effects found in other countries, do popular beliefs about "unlucky" days also influence the calendar of births?

We assume that without the effects exerted by the working calendar and/or by popular beliefs, the births should be equally distributed between the days of a month. We interpret the equal distribution as the expected one. This allows us to calculate a daily excess of births with respect to the expected number. We evaluate, by the means of multivariate regression, the impact of public holidays and of popular beliefs on the daily excess of births. In addition to working calendar effects, we found a depressing effect exerted by the 17th day of each month in all Italian territories. Indeed, the number 17 is considered extremely unlucky by popular tradition in Italy. We believe that these findings are indicative of a systemic abuse of elective delivery, especially in Southern Italy. To the best of our knowledge, this work is the first to analyze the effect of irrational beliefs on the calendar of births.
\end{abstract}

Keywords: Multivariate analysis, Birth seasonality, Elective delivery, Caesarean section, Superstitious beliefs

\section{Introduction}

In the decades preceding World War II, a commission of the International Institute of Statistics revealed that the birthdate of newborns was artificially modified in various countries. The phenomenon was ascertained in 16 out of 29 examined countries, and it assumed considerable quantitative consistency in five countries: Bulgaria, Japan, Italy, Poland and Serbia (Gini, 1934; Gini \& D'Addario, 1930). In particular, the falsifications were relative to the birthdates of the babies which occurred in the last days of a year, which were systematically registered as having happened in the first days of the following one.

(c) The Author(s). 2019 Open Access This article is distributed under the terms of the Creative Commons Attribution 4.0 International License (http://creativecommons.org/licenses/by/4.0/), which permits unrestricted use, distribution, and reproduction in any medium, provided you give appropriate credit to the original author(s) and the source, provide a link to the Creative Commons license, and indicate if changes were made. 
The Italian scholars of the epoch reconstructed the phenomenon as due to the deliberate intention of parents of postponing by one year the call for the compulsory military service for men, and to the desire to make female newborns appear younger (see Breschi, Gonano, \& Ruiu, 2018). It is useful to recall that, with exception of Lombardy, Piedmont and Liguria, Italy was an agriculturally based economy. Thus, the compulsory military service (which lasted 2 years) took away a free workforce from peasant families.

In addition to the artificial postponement of the new year, the empirical investigations (Gini, Naddeo, \& Passeggeri, 1954; Livi, 1929; Maroi, 1954) carried out on the birthdates of Italians highlighted other singular aspects of the daily distribution of live births. In particular, reluctance to report the correct date for those born on certain days of the week (Fig. 1), and particularly on Friday, a day considered ominous in popular tradition (see also Breschi \& Ruiu, 2016), was evident; conversely, Monday was the most frequent day of birth, and this was likely due to the fact that, especially in rural and mountain communities, the registry office was closed at the weekend (Gini et al., 1954). Another huge reduction in the number of births was evident on the 17th day of each month, and indeed, the number 17 is considered unlucky in Italy (see Breschi \& Ruiu, 2016); a similar effect was exerted by All Souls' Day (which falls on the 2 November). Furthermore, a huge depression in the number of births was registered on both the first day of the month and the last day of each month.

Despite these interesting peculiarities, the topic of the daily distribution of births has been completely neglected by Italian scholars in the second part of the twentieth century. Analyses carried out in other countries have shown that Sunday-born babies have almost disappeared (Lerchl \& Reinhard, 2008 for Switzerland; Lerchl, 2005 for Germany; Morikawa et al., 2016 for Japan), and in general, births occurring on public holidays are substantially lower than those on working days.

Unlike in the past, where for the sake of economic, cultural and religious reasons the date of birth was artificially modified, its occurrence nowadays is thanks to the technical possibility of anticipating and delaying delivery. In other words, the health system

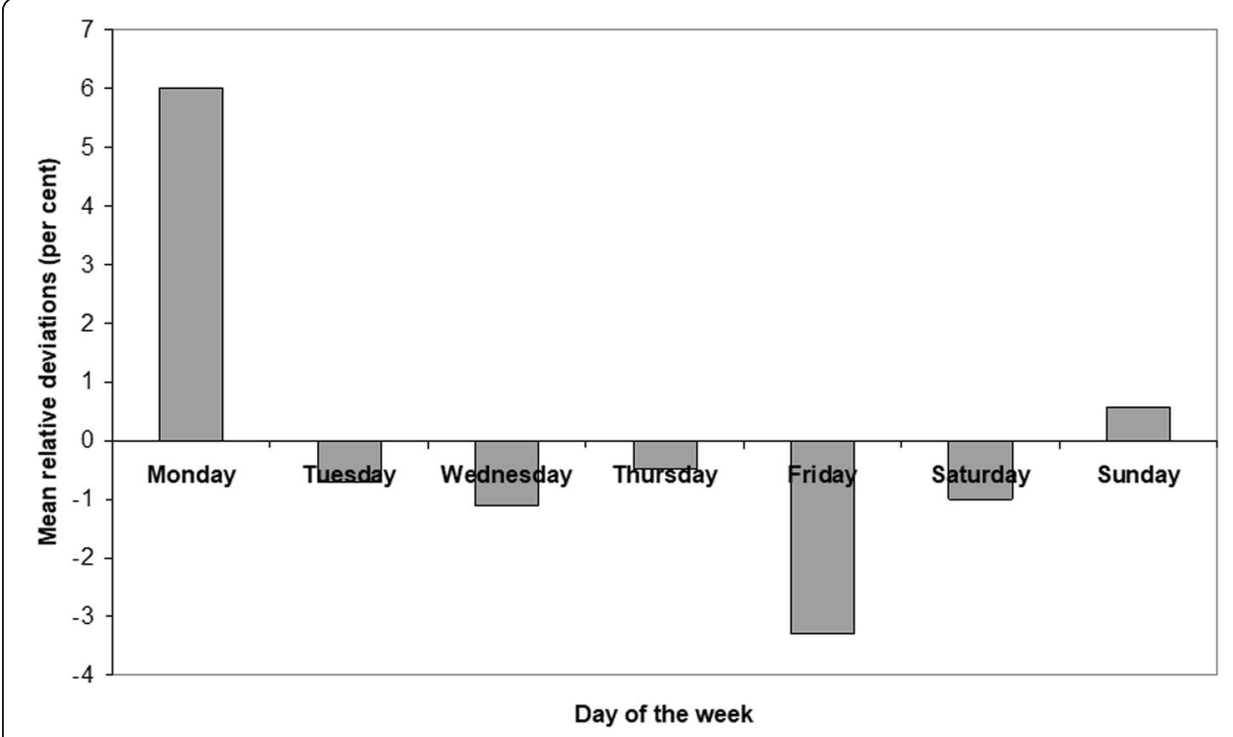

Fig. 1 Percentage difference of daily number of livebirths from the weekly average. Italy, 1951 
can intervene directly in the natural cycle of birth, thus creating an artificial calendar of births (see also Terzera 2002 for a discussion of other forms of artificilisation of births). This alteration has increased in recent years and to a great extent is associated with elective birth obtained by induction of labour or by elective caesarean section. In Italy, the use of this practice has been defined as "excessive" by the same Ministero della salute, 2017 (p.6): 35\% of the births that occurred in 2014 were, in fact, conducted by caesarean section. This is almost three times higher than the figure considered ideal by the World Health Organization (WHO, 2015). Furthermore, if we consider that in 2014 labour was induced in more than $15 \%$ of cases, we can conclude that, for half of the births, the time of delivery was more or less "driven". Figure 2 reports a comparison of the caesarean sections per 1000 live births in various European countries in 2014 (the most recent year for which the WHO reports statistics for Italy).

In order to evaluate whether or not the calendar of births is still modified to avoid inauspicious days (such as Friday or the 17th of each month) or if a depressing effect on the birth rate exists in Italy exerted by civil and religious feasts, we requested from ISTAT (the Italian Institute of Statistics) an ad hoc count of the daily births for the period 1999-2016. In compliance with the stringent privacy protection regulations (data is not provided when it involves less than ten events), it was possible to obtain the count of per-day births only at the level of the five macro-geographical regions (North West, North East, Centre, South and Islands). These data are however enough to highlight the existence of large differences in the practice of "adjusting the calendar" between the Southern area (South and Islands) and the rest of the country. In the following section, data and methods will be illustrated. In the third section, we will discuss the results, while the last section is devoted to final considerations.

\section{Methods and data}

The data used in this paper are the daily count of births for the five Italian macroregions (North West, North East, Centre, South, Islands) in the period 1 January 1999

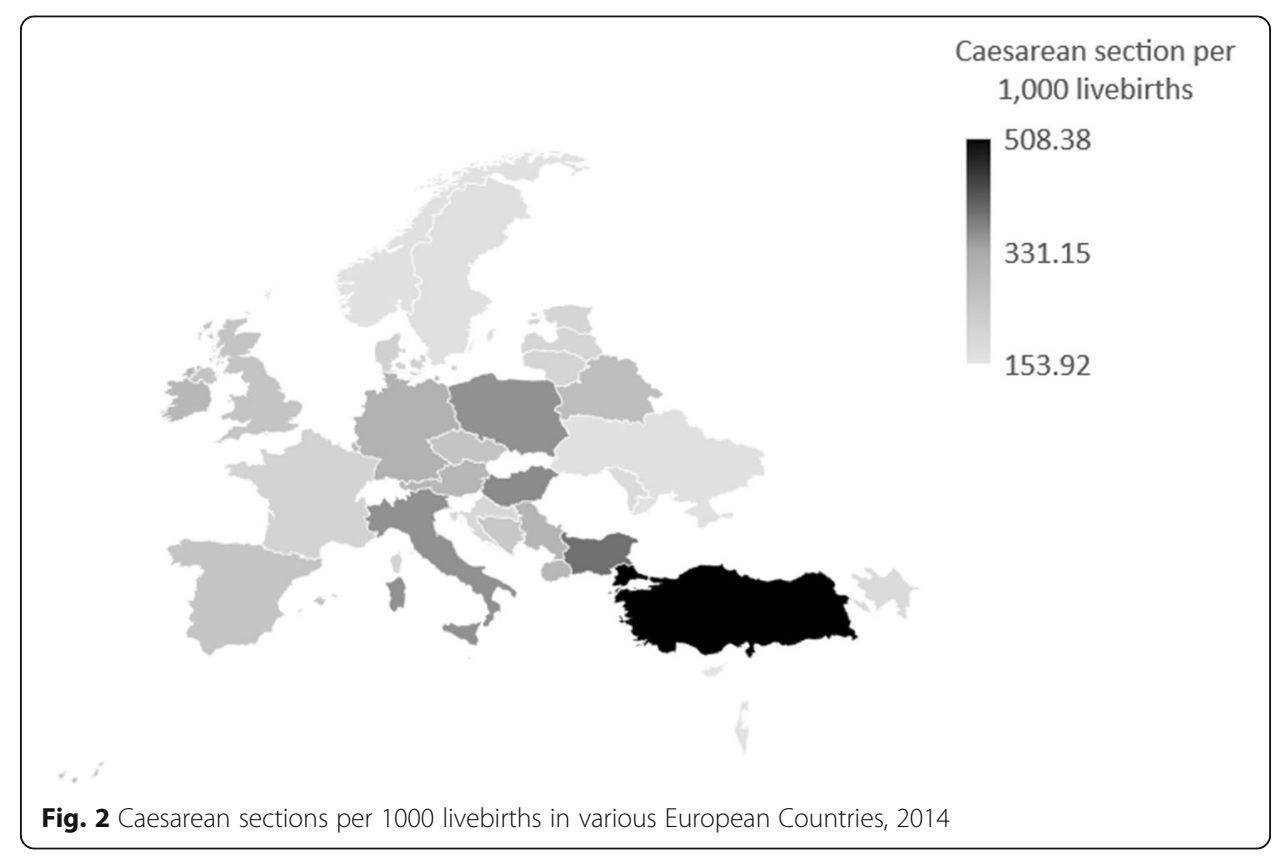


to 30 June 2016 and have been calculated, upon our formal request, by ISTAT from the "Rilevazione degli iscritti in anagrafe per nascita" (survey on the births transcribed in the registry office). The choice of the period depends exclusively on the data availability declared by ISTAT. The entire record for 2016 was available, but given that, especially for the second part of the year, the data were not definitive, we preferred to leave them out of the analysis.

First of all, as a first preliminary descriptive statistics, for each macro-region, we calculated an expected number of daily births $E(b)$ in a month $j$ by assuming equal distribution between the days of each month. In particular, it is calculated as follows:

$$
E\left(b_{j, t}\right)=\frac{\sum_{i=1}^{I} b_{i, j, t}}{I_{j, t}}
$$

where $b$ is the actual number of births, $i$ indicates the day of the month, $I$ is the last day of each month (i.e. 31 for January, $28 / 29$ for February, ...), $j=[1,2, \ldots, 12]$ is the month and $t=[1999,2000, \ldots, 2015]$ is the year. We used (1) to derive an excess birth rate for each day $\pi\left(b_{i, j, t}\right)$ as follows:

$$
\begin{aligned}
\pi\left(b_{i, j, t}\right) & =\frac{b_{i, j, t}-E\left(b_{j, t}\right)}{E\left(b_{j, t}\right)} \cdot 100 \text { for } i=[1,2, \ldots, I], j=[1,2, \ldots, 12], t \\
& =[1999,2000, \ldots, 2015]
\end{aligned}
$$

A similar indicator has been used also by Peña (2015) for analyzing the excess mortality on birthdays.

In Table 1 , we report the average $\overline{\pi\left(b_{i, j}\right)}$ which occurred for each day of the month in the period 1999-2015. The period under analysis has been limited to this interval to avoid a different denominator in the calculation of the average excess of births between the first 6 months (17 years) and the last semester (16 years). With the exception of this descriptive statistics, all the other analyses will consider the complete interval 1 January 1999 to 30 June 2016.

The 17th day of the month represents the most negative $\overline{\pi\left(b_{i, j}\right)}$ in 2 months (March and October), the civil feasts of the 25 April and the 1 May are minimal in the respective months, and interestingly, the 29 February seems to be strongly avoided in leap years. Also, religious feasts such as Christmas, the Assumption, and All Saints' Day exert similar depressing effects on births with an increase a few days later.

The daily count of births will be used as a dependent variable in a negative binomial regression (it will be shown that the test for over-dispersion indicates that negative binomial regression should be preferred to Poisson regression) where the independents are a dummy for each day of the month (taking the 15th day as a reference), a dummy for the day of the week (taking Wednesday as reference), and a dummy equal to one from the 24 December to the 26 December (named Christmas). We also included a dummy equal to one for the last and first day of the year, a dummy capturing other religious feasts such as Easter, the feast of the Assumption celebrated on 15 August, the All Saints' Day (1 November), and the Epiphany (6 January); a dummy for capturing Italian civil feasts such as Labour Day, the Italian liberation from Nazi fascism which is celebrated on 25 April, the 2 June on which the birth of the Republic is celebrated; and 
Table 1 Average excess of births in each day of the months, Italy 1999-2015

\begin{tabular}{|c|c|c|c|c|c|c|c|c|c|c|c|c|}
\hline \multirow[t]{2}{*}{ Day } & \multicolumn{12}{|l|}{ Month } \\
\hline & 1 & 2 & 3 & 4 & 5 & 6 & 7 & 8 & 9 & 10 & 11 & 12 \\
\hline 1 & -29.11 & -0.44 & 3.20 & -8.04 & -24.69 & -1.98 & -3.23 & 1.45 & -7.31 & 6.69 & -22.59 & 3.39 \\
\hline 2 & 0.80 & 0.66 & 3.34 & 0.35 & -0.89 & -21.37 & -1.95 & 2.32 & -5.01 & 5.32 & -15.96 & 2.38 \\
\hline 3 & 8.67 & -0.17 & 4.42 & 0.61 & 3.35 & -2.16 & -1.94 & 3.01 & -3.36 & 4.69 & 5.53 & 5.06 \\
\hline 4 & 7.24 & 0.44 & 2.87 & -0.66 & 3.40 & 0.30 & -1.98 & 2.94 & -4.97 & 6.00 & 6.88 & 3.45 \\
\hline 5 & 5.61 & -0.78 & 3.38 & -4.16 & 4.14 & -0.34 & -2.01 & 4.10 & -4.85 & 3.81 & 5.89 & 3.11 \\
\hline 6 & -24.08 & -0.03 & 2.18 & -4.56 & 2.01 & -0.38 & -2.33 & 5.16 & -4.41 & 2.89 & 5.83 & 1.86 \\
\hline 7 & 5.49 & -0.10 & 2.82 & 0.08 & 3.21 & -2.06 & -0.49 & 3.99 & -3.29 & 2.36 & 2.81 & 1.12 \\
\hline 8 & 4.72 & 0.03 & 0.51 & 0.40 & 3.84 & -0.35 & 1.38 & 4.38 & -4.71 & 1.91 & 2.78 & -24.23 \\
\hline 9 & 2.33 & 0.01 & -1.55 & -4.14 & 0.21 & -1.50 & -1.06 & 3.56 & -0.57 & 1.94 & 3.71 & -0.30 \\
\hline 10 & 3.80 & -0.31 & 0.87 & -0.81 & 2.62 & -1.73 & 0.36 & 4.71 & -1.82 & 0.80 & 2.73 & 5.49 \\
\hline 11 & 2.59 & 1.32 & 0.77 & -1.63 & 2.01 & 0.75 & -1.38 & 2.83 & -1.61 & 0.47 & 3.75 & 2.35 \\
\hline 12 & 1.53 & -0.70 & 2.18 & -1.09 & 3.07 & 0.49 & 0.35 & 2.43 & -1.43 & -0.74 & 4.12 & 2.27 \\
\hline 13 & 0.54 & -2.45 & 0.28 & -5.48 & 1.20 & -2.43 & -1.31 & 1.52 & -1.84 & -2.46 & 1.48 & 0.97 \\
\hline 14 & 3.16 & 3.40 & -0.69 & -1.11 & 2.13 & 0.25 & 1.24 & -4.09 & -0.41 & -2.71 & 1.20 & 1.21 \\
\hline 15 & 4.08 & 0.61 & 1.83 & 1.27 & 3.79 & 1.22 & -0.28 & -26.60 & 2.73 & 1.71 & 1.63 & 4.11 \\
\hline 16 & 1.63 & 0.44 & -0.66 & 0.48 & 0.40 & 1.82 & 2.12 & -5.82 & 1.80 & -1.39 & 1.67 & 4.16 \\
\hline 17 & -2.13 & -4.06 & -6.39 & -5.70 & -3.05 & -3.73 & -2.82 & -4.83 & -1.26 & -7.84 & -3.31 & 1.08 \\
\hline 18 & 0.80 & 2.39 & 0.92 & 2.27 & 1.64 & 3.88 & 0.51 & 2.77 & 4.09 & -0.84 & 1.29 & 10.68 \\
\hline 19 & 1.54 & 0.50 & 3.31 & 2.54 & 2.95 & 0.79 & 0.69 & 1.02 & 3.39 & -3.90 & 0.45 & 9.06 \\
\hline 20 & 2.53 & 0.06 & 0.43 & 4.18 & 1.01 & 1.49 & 1.47 & 3.44 & 4.76 & -1.93 & 1.27 & 12.32 \\
\hline 21 & 3.20 & 0.93 & 0.27 & -1.16 & 0.03 & 2.17 & 0.36 & 0.90 & 3.25 & -1.93 & -0.38 & 7.69 \\
\hline 22 & 1.24 & 0.01 & -0.78 & 1.39 & -0.09 & 0.57 & -0.57 & -1.32 & 2.96 & -2.14 & -0.90 & 3.75 \\
\hline 23 & 0.56 & -0.16 & -0.78 & 5.78 & -1.71 & 2.79 & 2.73 & -0.93 & 4.90 & -2.25 & -1.02 & -0.40 \\
\hline 24 & 1.28 & -0.75 & -3.28 & 6.31 & -0.55 & 3.25 & 1.22 & -0.64 & 5.59 & -4.69 & 0.32 & -13.06 \\
\hline 25 & -0.19 & 0.52 & -2.05 & -22.07 & -0.64 & 4.32 & 0.58 & -0.86 & 4.40 & -2.13 & -0.81 & -33.33 \\
\hline 26 & -1.16 & -0.65 & -0.88 & 3.77 & -1.18 & 3.84 & 1.48 & -0.77 & 2.25 & -2.62 & -0.20 & -23.75 \\
\hline 27 & 0.11 & -1.91 & -1.56 & 7.90 & -1.68 & 2.61 & 1.28 & -0.58 & 1.86 & -1.55 & -0.79 & 15.86 \\
\hline 28 & -0.24 & -0.43 & -4.55 & 7.39 & -0.05 & 3.15 & 0.97 & 0.86 & 0.53 & -0.52 & -2.27 & 13.18 \\
\hline 29 & -1.47 & -18.04 & -4.77 & 6.42 & -1.26 & 0.70 & 1.40 & -2.34 & 2.77 & 0.01 & -2.49 & 2.87 \\
\hline 30 & -2.71 & & -2.39 & 9.46 & -2.41 & 3.63 & 2.53 & -0.36 & 1.57 & 1.29 & -2.62 & -4.26 \\
\hline 31 & -2.37 & & -3.25 & & -2.80 & & 0.71 & -2.26 & & -0.23 & & -18.09 \\
\hline
\end{tabular}

Notes: The minimum for each month are in bold, and the maximum are italics; since the last months of the 2016 were drop from the analysis, to calculate the mean using the same number of years for each combination day-month, we limited this table to the period 1999-2015

a dummy for the 2 November. Also, an interaction between the day 17 and Friday will be inserted in the model (fri_17). Indeed, according to population tradition, the combination of Friday with the number 17 represents the most unlucky day in the year (in other words, it is the Italian equivalent of Friday 13th in the Anglo-Saxon countries). We will run two separate analyses for the two sexes, to evaluate if a gender difference exists in the strategy of avoiding a delivery on an inauspicious day (see Mussino et al 2018 for a discussion of sex preferences for children). We will also run both separated analyses for each macro-region and a pooled analysis. In the latter analysis, we will include in addition to a dummy for each macro-area also a control for the different level of economic development (through the real GDP per capita chain linked with reference year 2010). We also add the percentage of births happened by caesarean section on 
total births (the variable is named ces_rate, data for 2016 are not available). However, since it is reasonable to assume that the avoidance of the day 17 is easier the more frequent the recourse to the caesarean section, we have to interact the dummy associated to this day with ces_rate. As reported by Norton, Wang, and Ai (2004), differently from linear model, the coefficient associated to an interaction term in nonlinear model does not completely represent the underlying interaction effect. This problem does not apply to incidence rate ratios (IRR), which could be derived from negative binomial regression coefficients, when two categorical variables are interacted (see Hilbe, 2011, p. 526-7). For this reason, we categorized the variable ces_rate on the basis of the values of its quartiles and created the interaction between the dummy associated to day 17 and the category of the ces_rate (using the first quartile as reference). In Fig. $3 \mathrm{a}$ and b, we report the evolution over time of both the GDP per capita and the caesarean rate for each macro-area.

We have also run the same analyses but using the $\pi\left(b_{i, j, t}\right)$ as the dependent variable and implementing a multivariate linear regression instead of the negative binomial model. The results (not reported here) did not change a lot and are available upon request to the authors.

We want to remark that there is an ongoing debate in social science (Gorard, 2007; Jones, Johnston, Manley, Owen, \& Charlton, 2015) on the legitimacy of the estimating model and making inferences on the parameters when a researcher has data covering the total population (in our case the total number of births). On the one hand, Gorard sustains that only descriptive statistics are needed in this case. On the other, Jones et al. maintain that using inference to account for uncertainty is necessary, especially when there are small numbers for some cells of the tabulation, even in cases where the latter is derived from census data. Indeed, in similar circumstances, a simple descriptive statistic can vary a lot from 1 year to another (reflecting the natural variation of the phenomenon under analysis) thus indicating misleading conclusions. Considering for instance that in 2016 for the macro-area Islands, we know that in April, the average daily number of male newborns was 63 , with a minimum of 42 and a maximum of 85 , we seem to be in the situation described by Jones et al.

We do not want to contribute to this debate; however, we decided to report standard errors and associated significance levels, but our main comments will be focused on the magnitude of the parameters.

\section{Empirical results}

In Table 2, we report the results for the above depicted negative binomial regressions using the daily count of birth calculated for male babies as the dependent variable. Columns 1-5 report the results associated respectively with the North West, North East, Centre, South and Islands. Note that Table 2 reports incidence rate ratios (IRR) instead of regression coefficients.

At the end of the table, we report the result of the test of significance of the dispersion parameter. Refusing the null implies that the negative binomial should be preferred to the Poisson model, since the hypothesis of the absence of overdispersion on which the Poisson regression model is built is violated.

The results indicate that in comparison with Wednesday, in the North West/North East, the rate of daily male births would be expected to decrease by a factor of 0.77 on 


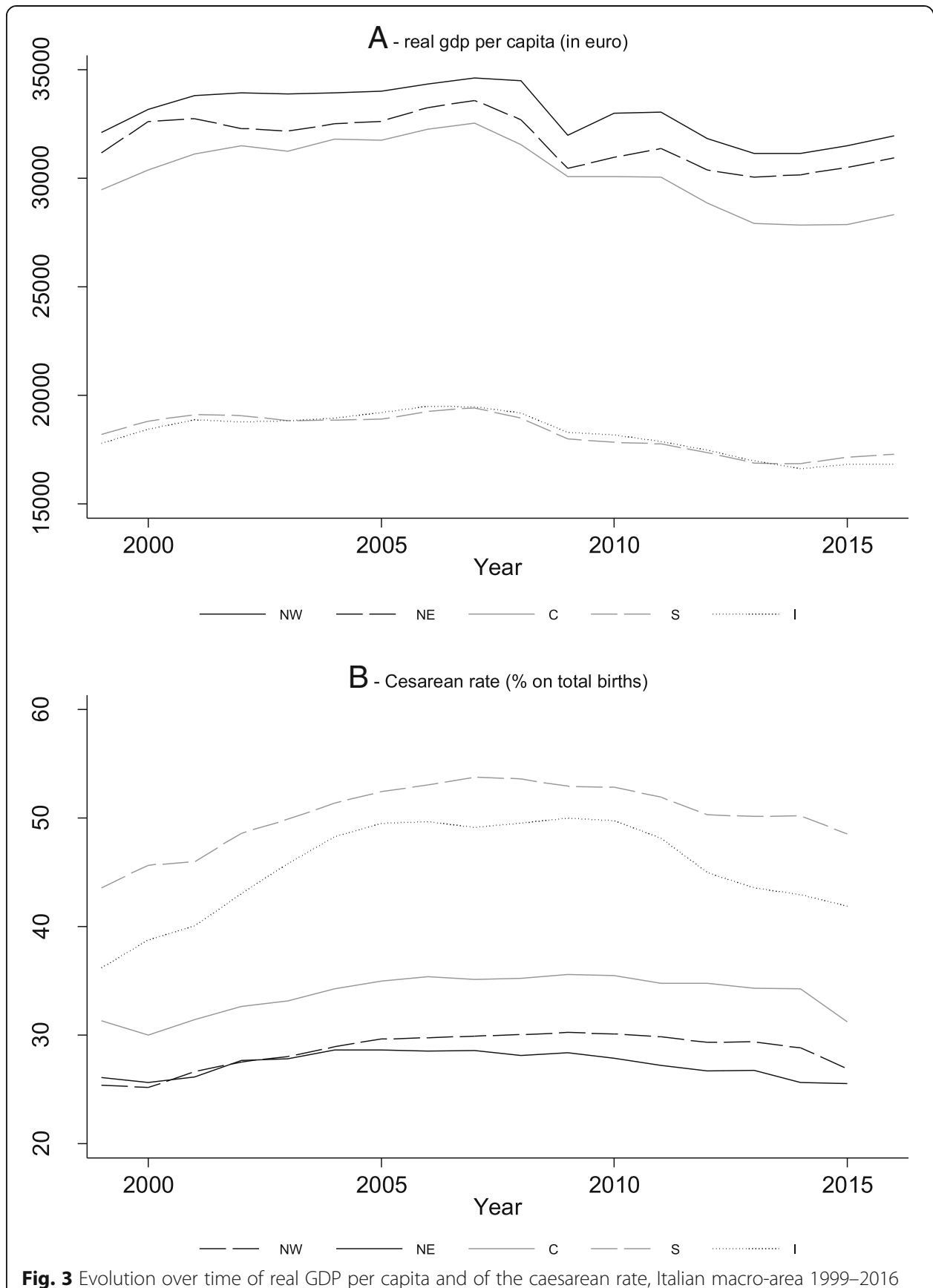

Sundays. The result about Saturday also indicates that few births happen on this day with respect to Wednesday. In Southern Italy, the strongest weekend effect is observed: we have that the incidence rate of Sunday is 0.56 times the incidence of Wednesday. Furthermore, also the incidence ratio associated with Friday compared to Wednesday is reduced by a factor of 0.959 . A strong weekend effect characterises also the Islands. However, in the Islands, in contrast to the South, the incidence rate associated to Friday seems to be not different with respect to Wednesday. The Centre of Italy seems to be characterised by an intermediate situation: the weekend effect is similar to that registered in the North, but as in the South, the depressing effect starts from Friday. In 
Table 2 The calendar effect on the daily male births, Italian macro-areas 1 January 1999 to 30 June 2016

\begin{tabular}{|c|c|c|c|c|c|c|c|c|c|c|}
\hline \multirow[t]{2}{*}{ Variables } & \multicolumn{2}{|l|}{$1-N W$} & \multicolumn{2}{|l|}{ 2-NE } & \multicolumn{2}{|l|}{$3-c$} & \multicolumn{2}{|l|}{$4-5$} & \multicolumn{2}{|l|}{$5-15$} \\
\hline & IRR & S.E. & $\overline{I R R}$ & S.E. & IRR & S.E. & IRR & S.E. & $\overline{\text { IRR }}$ & S.E. \\
\hline \multicolumn{11}{|l|}{ Day of the month } \\
\hline 1 & $0.980^{* *}$ & $(0.008)$ & 0.989 & $(0.009)$ & $0.980^{* *}$ & (0.009) & $0.977^{* *}$ & $(0.010)$ & $0.974^{* *}$ & $(0.012)$ \\
\hline 2 & $0.982^{* *}$ & $(0.008)$ & $0.982^{*}$ & (0.009) & 0.994 & $(0.009)$ & 0.997 & $(0.010)$ & 0.992 & $(0.013)$ \\
\hline 3 & 0.991 & $(0.008)$ & 0.995 & (0.009) & 1.009 & $(0.009)$ & 1.009 & $(0.010)$ & $1.022^{*}$ & $(0.012)$ \\
\hline 4 & 0.995 & $(0.008)$ & 0.999 & (0.009) & 1.001 & $(0.009)$ & $1.017^{*}$ & $(0.010)$ & $1.021^{*}$ & $(0.012)$ \\
\hline 5 & 0.991 & $(0.008)$ & 1.006 & $(0.009)$ & 1.007 & $(0.009)$ & 1.002 & $(0.010)$ & 1.010 & $(0.012)$ \\
\hline 6 & 0.988 & $(0.008)$ & 0.995 & $(0.009)$ & 0.996 & $(0.009)$ & 0.998 & $(0.010)$ & 0.999 & $(0.012)$ \\
\hline 7 & $0.981^{* *}$ & $(0.008)$ & 0.995 & (0.009) & 0.997 & $(0.009)$ & 1.009 & $(0.010)$ & 1.009 & $(0.012)$ \\
\hline 8 & $0.981^{* *}$ & $(0.008)$ & 0.995 & (0.009) & 1.003 & $(0.009)$ & 0.997 & $(0.010)$ & 1.003 & $(0.012)$ \\
\hline 9 & $0.981^{* *}$ & $(0.008)$ & $0.982^{* *}$ & $(0.009)$ & 0.998 & $(0.009)$ & 0.997 & $(0.010)$ & 0.993 & $(0.012)$ \\
\hline 10 & $0.981^{* *}$ & $(0.008)$ & $0.983^{* *}$ & (0.009) & 0.993 & $(0.009)$ & 0.999 & $(0.010)$ & 1.006 & $(0.012)$ \\
\hline 11 & $0.977^{* * *}$ & $(0.008)$ & $0.983^{*}$ & $(0.009)$ & $0.982^{* *}$ & (0.009) & 1.002 & $(0.010)$ & 1.015 & $(0.012)$ \\
\hline 12 & $0.981^{* *}$ & (0.008) & 0.990 & (0.009) & 0.996 & (0.009) & 1.001 & $(0.010)$ & 1.006 & $(0.012)$ \\
\hline 13 & $0.974^{* * *}$ & $(0.008)$ & $0.977^{* * *}$ & (0.009) & $0.972^{* * *}$ & $(0.009)$ & 0.986 & $(0.010)$ & 0.981 & $(0.012)$ \\
\hline 14 & $0.986^{*}$ & $(0.008)$ & 0.996 & $(0.009)$ & $0.984^{*}$ & $(0.009)$ & $0.978^{* *}$ & $(0.009)$ & 0.987 & $(0.012)$ \\
\hline 15 & \multicolumn{2}{|l|}{ Ref } & \multicolumn{2}{|l|}{ Ref } & \multicolumn{2}{|l|}{ Ref } & \multicolumn{2}{|l|}{ Ref } & \multicolumn{2}{|l|}{ Ref } \\
\hline 16 & $0.986^{*}$ & $(0.008)$ & 0.995 & (0.009) & 0.995 & $(0.009)$ & $0.984^{*}$ & $(0.010)$ & 1.000 & $(0.012)$ \\
\hline 17 & $0.960^{* * *}$ & $(0.008)$ & $0.973^{* * *}$ & (0.009) & $0.952^{* * *}$ & $(0.009)$ & $0.918^{* * *}$ & (0.009) & $0.963^{* * *}$ & $(0.012)$ \\
\hline 18 & 0.999 & $(0.008)$ & 0.996 & $(0.009)$ & 0.997 & $(0.009)$ & $1.019^{*}$ & $(0.010)$ & 1.015 & $(0.012)$ \\
\hline 19 & 0.988 & $(0.008)$ & 0.996 & (0.009) & 1.001 & $(0.009)$ & 1.001 & $(0.010)$ & $1.022^{*}$ & $(0.012)$ \\
\hline 20 & 0.997 & $(0.008)$ & 1.005 & (0.009) & 1.011 & $(0.009)$ & $1.020^{* *}$ & $(0.010)$ & $1.026^{* *}$ & (0.013) \\
\hline 21 & $0.984^{* *}$ & $(0.008)$ & 0.986 & $(0.009)$ & 1.001 & $(0.009)$ & 1.006 & $(0.010)$ & 1.015 & $(0.012)$ \\
\hline 22 & 0.987 & (0.008) & 0.994 & (0.009) & 0.986 & $(0.009)$ & $0.974^{* * *}$ & (0.009) & 0.991 & $(0.012)$ \\
\hline 23 & 0.995 & (0.008) & 0.994 & (0.009) & 0.999 & $(0.009)$ & $0.978^{* *}$ & (0.009) & 1.012 & $(0.012)$ \\
\hline 24 & 0.996 & (0.008) & 1.008 & (0.009) & 1.003 & $(0.009)$ & 0.990 & $(0.010)$ & 1.016 & $(0.013)$ \\
\hline 25 & $0.984^{*}$ & (0.008) & 0.987 & (0.009) & 0.990 & (0.009) & $0.969^{* * *}$ & $(0.010)$ & 0.987 & $(0.012)$ \\
\hline 26 & $0.978^{* * *}$ & $(0.008)$ & $0.980^{* *}$ & (0.009) & 0.996 & $(0.009)$ & $0.983^{*}$ & $(0.010)$ & 0.996 & $(0.012)$ \\
\hline 27 & $0.986^{*}$ & (0.008) & 0.992 & (0.009) & 1.001 & $(0.009)$ & 1.005 & $(0.010)$ & $1.022^{*}$ & $(0.012)$ \\
\hline 28 & 0.997 & $(0.008)$ & 0.994 & $(0.009)$ & 0.995 & $(0.009)$ & 0.999 & $(0.010)$ & 1.020 & $(0.012)$ \\
\hline 29 & $0.979 * *$ & $(0.008)$ & 0.987 & (0.009) & $0.981^{* *}$ & (0.009) & $0.980^{* *}$ & $(0.010)$ & 0.988 & $(0.012)$ \\
\hline 30 & $0.986^{*}$ & $(0.008)$ & 0.991 & (0.009) & 0.991 & $(0.009)$ & $0.978^{* *}$ & $(0.010)$ & 0.993 & $(0.012)$ \\
\hline 31 & $0.972^{* * *}$ & $(0.010)$ & 0.988 & $(0.011)$ & $0.982^{*}$ & $(0.011)$ & $0.979^{*}$ & $(0.011)$ & 1.015 & $(0.015)$ \\
\hline \multicolumn{11}{|l|}{ Day of the week } \\
\hline Sunday & $0.774^{* * *}$ & $(0.003)$ & $0.770^{* * *}$ & $(0.003)$ & $0.727^{* * *}$ & $(0.003)$ & $0.562^{* * *}$ & $(0.003)$ & $0.627^{* * *}$ & $(0.004)$ \\
\hline Monday & 1.003 & $(0.004)$ & $0.985^{* * *}$ & $(0.004)$ & $0.974^{* * *}$ & $(0.004)$ & $0.979 * * *$ & $(0.004)$ & 1.003 & $(0.006)$ \\
\hline Tuesday & $1.039^{* * *}$ & $(0.004)$ & $1.016^{* * *}$ & $(0.004)$ & $1.037^{* * *}$ & $(0.004)$ & $1.046^{* * *}$ & $(0.005)$ & $1.085^{* * *}$ & \\
\hline Wednesday & \multicolumn{2}{|c|}{ Ref } & \multicolumn{2}{|c|}{ Ref } & \multicolumn{2}{|c|}{ Ref } & \multicolumn{2}{|c|}{ Ref } & \multicolumn{2}{|c|}{ Ref } \\
\hline Thursday & $1.040^{* * *}$ & $(0.004)$ & 1.002 & $(0.004)$ & $1.019^{* * *}$ & $(0.004)$ & $0.991^{*}$ & $(0.004)$ & $1.023^{* * *}$ & $(0.006)$ \\
\hline Friday & $1.018^{* * *}$ & $(0.004)$ & $1.025^{* * *}$ & $(0.004)$ & $0.989^{* *}$ & $(0.004)$ & $0.957^{* * *}$ & $(0.004)$ & $1.022^{* * *}$ & $(0.006)$ \\
\hline Saturday & $0.827^{* * *}$ & $(0.003)$ & $0.837^{* * *}$ & $(0.004)$ & $0.867^{* * *}$ & $(0.004)$ & $0.800^{* * *}$ & $(0.004)$ & $0.817^{* * *}$ & $(0.005)$ \\
\hline Fri_17 & 0.998 & $(0.017)$ & 0.992 & $(0.018)$ & $0.967^{*}$ & (0.019) & $0.930^{* * *}$ & $(0.019)$ & 0.972 & $(0.024)$ \\
\hline $\begin{array}{l}\text { End/first of the } \\
\text { year }\end{array}$ & $0.828^{* * *}$ & $(0.013)$ & $0.836^{* * *}$ & $(0.015)$ & $0.766^{* * *}$ & $(0.014)$ & $0.617^{* * *}$ & $(0.013)$ & $0.676^{* * *}$ & $(0.018)$ \\
\hline
\end{tabular}


Table 2 The calendar effect on the daily male births, Italian macro-areas 1 January 1999 to 30 June 2016 (Continued)

\begin{tabular}{|c|c|c|c|c|c|c|c|c|c|c|}
\hline \multirow[t]{2}{*}{ Variables } & \multicolumn{2}{|l|}{$1-N W$} & \multicolumn{2}{|l|}{ 2-NE } & \multicolumn{2}{|l|}{$3-c$} & \multicolumn{2}{|l|}{ 4-S } & \multicolumn{2}{|l|}{$5-15$} \\
\hline & IRR & S.E. & IRR & S.E. & IRR & S.E. & IRR & S.E. & IRR & S.E. \\
\hline Civil feast & $0.850^{* * *}$ & $(0.011)$ & $0.851^{* * *}$ & $(0.012)$ & $0.783^{* * *}$ & $(0.012)$ & $0.668^{* * *}$ & $(0.011)$ & $0.705^{* * *}$ & $(0.015)$ \\
\hline Christmas & $0.823^{* * *}$ & $(0.011)$ & $0.823^{* * *}$ & $(0.012)$ & $0.782^{* * *}$ & $(0.012)$ & $0.611^{* * *}$ & $(0.011)$ & $0.670^{* * *}$ & $(0.014)$ \\
\hline Other rel. feast & $0.844^{* * *}$ & $(0.008)$ & $0.835^{* * *}$ & $(0.008)$ & $0.793^{* * *}$ & $(0.008)$ & $0.666^{* * *}$ & $(0.008)$ & $0.675^{* * *}$ & $(0.010)$ \\
\hline All Souls' day & $0.916^{* * *}$ & $(0.020)$ & $0.927^{* * *}$ & $(0.023)$ & $0.828^{* * *}$ & $(0.021)$ & $0.756^{* * *}$ & $(0.021)$ & $0.773^{* * *}$ & $(0.027)$ \\
\hline$N$ & \multicolumn{2}{|l|}{6391} & \multicolumn{2}{|l|}{6391} & \multicolumn{2}{|l|}{6391} & \multicolumn{2}{|l|}{6391} & \multicolumn{2}{|l|}{6391} \\
\hline Pseudo $R^{2}$ & \multicolumn{2}{|l|}{0.131} & \multicolumn{2}{|l|}{0.125} & \multicolumn{2}{|l|}{0.130} & \multicolumn{2}{|l|}{0.177} & \multicolumn{2}{|l|}{0.148} \\
\hline $\begin{array}{l}\text { Likelihood-ratio } \\
\text { test of alpha }=0 \\
\text { (chi- } p \text { value) }\end{array}$ & \multicolumn{2}{|c|}{$\begin{array}{c}308.8 \\
(p \text { value } 0.000)\end{array}$} & \multicolumn{2}{|c|}{$\begin{array}{c}90.2 \\
\text { ( } p \text { value } 0.000)\end{array}$} & \multicolumn{2}{|c|}{$\begin{array}{c}147.5 \\
(p \text { value } 0.000)\end{array}$} & \multicolumn{2}{|c|}{$\begin{array}{c}1271 \\
(p \text { value } 0.000)\end{array}$} & \multicolumn{2}{|c|}{$\begin{array}{c}251.1 \\
(p \text { value } 0.000)\end{array}$} \\
\hline
\end{tabular}

Exponentiated coefficients reported. Controlling for month of birth and for year fixed effects. Standard errors in parentheses

${ }^{*} p<0.10,{ }^{* *} p<0.05,{ }^{* * *} p<0.01$

all the macro-regions, Tuesday is characterised by the highest increase in the IRR with respect to the reference category. A possible interpretation is that this represents the day in which the working activities are postponed from the weekend.

When the day of the month is considered, the 17th turns out to be the day on which the incidence rate is lowest for all the macro-areas in comparison with the reference category. The strongest depressing effect is again registered in Southern Italy: the incidence rate associated with the 17th day of the month would be expected to decrease by a factor of 0.918 with respect to that associated to the 15th day. When the 17th day of a month is also Friday, we estimated a further decrease of the IRR by a factor of 0.93 in the South (this is the only macro-area where the result is strongly significant from a statistical point of view). Note that with respect to the simple descriptive statistics reported in Table 1, the multivariate regression allows us to control out for the effect of the day of the week and of religious/civil feasts, and thus to better highlight the depressing effect of this day. In addition, religious and civil feasts can depress births, with stronger effects in the South (followed by the Islands). It is worthwhile noting that even though All Souls' Day is a religious festival in which according to tradition the dead are commemorated, in contrast to Christmas, Easter, etc., public offices are not closed on this day. So, a hospital may decide not to schedule births during public holidays in order to avoid bearing the costs of the extra compensation due to workers for having worked on these days while the choice to not schedule births on All Souls' Day seems to be the result of a deliberate choice to avoid correspondence between future birthdays of the newborn and the day of the dead commemoration.

In Table 3, we repeat the same analysis reported in Table 2 but using female births. The results are roughly the same, with three important exceptions: in the Centre, the 17th of the month seems to exert a weaker effect for females than for males, while conversely, in the North, the effect on female births is slightly stronger than on male births; in the North-West, also the interaction between Friday and the 17th day implies a further depressing effect.

If one is willing to accept the idea that the avoidance of this day is driven by superstitious beliefs, these results could be interpreted as evidence of the existence of different gender preferences in protecting the children against an unlucky day. 
Table 3 The calendar effect on the daily female births in Italian macro-areas from 1 January 1999 to 30 June 2016

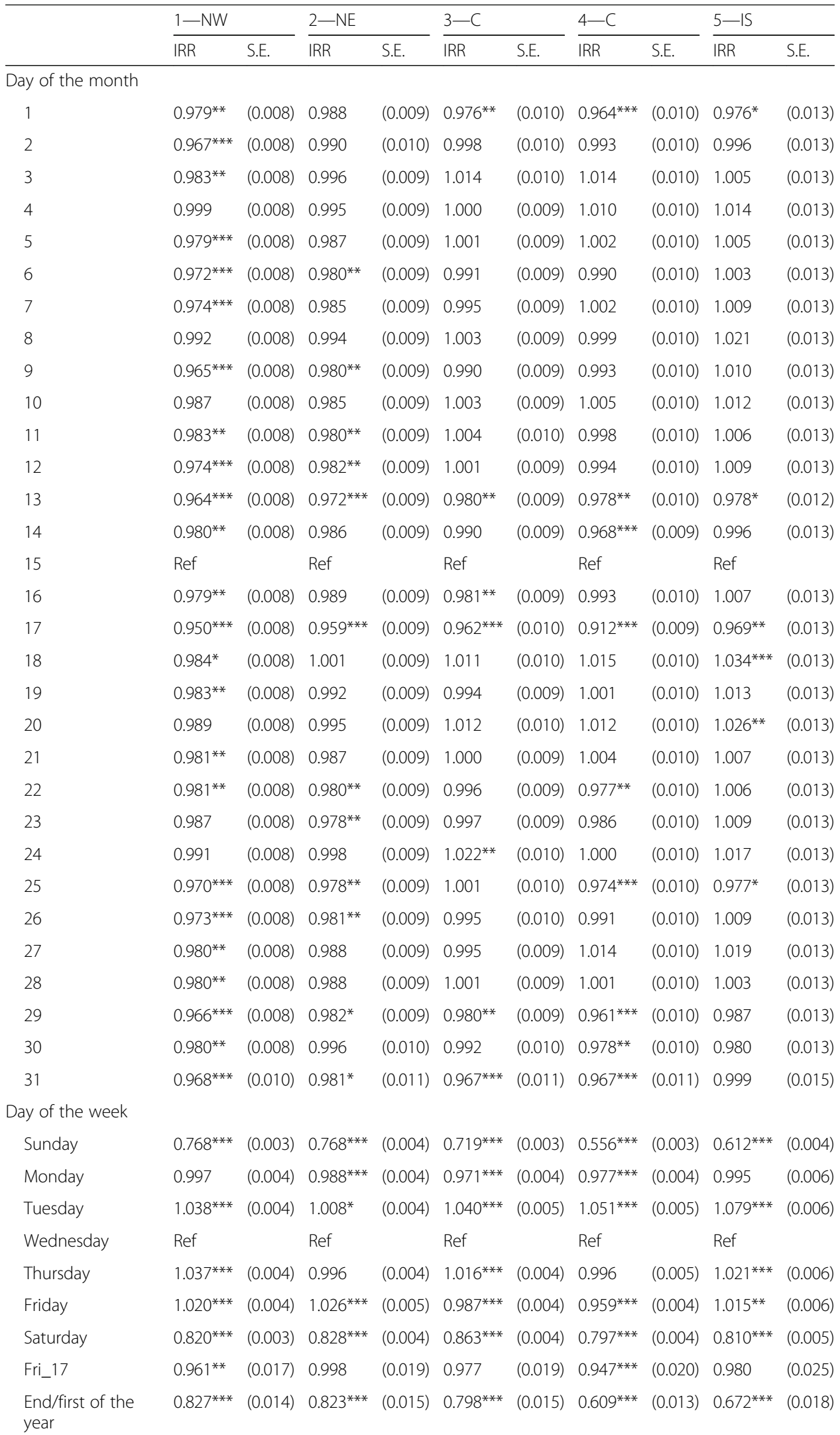


Table 3 The calendar effect on the daily female births in Italian macro-areas from 1 January 1999 to 30 June 2016 (Continued)

\begin{tabular}{|c|c|c|c|c|c|c|c|c|c|c|}
\hline & \multicolumn{2}{|l|}{$1-N W$} & \multicolumn{2}{|l|}{$2-N E$} & \multicolumn{2}{|l|}{$3-c$} & \multicolumn{2}{|l|}{$4-C$} & \multicolumn{2}{|l|}{$5-15$} \\
\hline & IRR & S.E. & IRR & S.E. & IRR & S.E. & IRR & S.E. & IRR & S.E. \\
\hline Civil feast & $0.860^{* * *}$ & $(0.011)$ & $0.848^{* * *}$ & $(0.013)$ & $0.785^{* * *}$ & $(0.012)$ & $0.669^{* * *}$ & $(0.011)$ & $0.688^{* * *}$ & $(0.015)$ \\
\hline Christmas & $0.803^{* * *}$ & $(0.011)$ & $0.817^{* * *}$ & $(0.013)$ & $0.759^{* * *}$ & $(0.012)$ & $0.602^{* * *}$ & $(0.011)$ & $0.661^{* * *}$ & $(0.015)$ \\
\hline Other rel. Feast & $0.817^{* * *}$ & $(0.008)$ & $0.831^{* * *}$ & (0.009) & $0.798^{* * *}$ & (0.009) & $0.639^{* * *}$ & $(0.008)$ & $0.680^{* * *}$ & $(0.011)$ \\
\hline All Souls' day & $0.889^{* * *}$ & $(0.020)$ & $0.907^{* * *}$ & $(0.023)$ & $0.847^{* * *}$ & $(0.022)$ & $0.718^{* * *}$ & $(0.020)$ & $0.807^{* * *}$ & $(0.029)$ \\
\hline N & \multicolumn{2}{|l|}{6391} & \multicolumn{2}{|l|}{6391} & \multicolumn{2}{|l|}{6391} & \multicolumn{2}{|l|}{6391} & \multicolumn{2}{|l|}{6391} \\
\hline Pseudo $R^{2}$ & \multicolumn{2}{|l|}{0.134} & \multicolumn{2}{|l|}{0.119} & \multicolumn{2}{|l|}{0.130} & \multicolumn{2}{|l|}{0.180} & \multicolumn{2}{|l|}{0.150} \\
\hline $\begin{array}{l}\text { Likelihood-ratio } \\
\text { test of alpha }=0 \\
\text { (chi-pvalue) }\end{array}$ & \multicolumn{2}{|c|}{$240.1(0.000)$} & \multicolumn{2}{|c|}{$146.3(0.000)$} & \multicolumn{2}{|c|}{$159.02(0.000)$} & \multicolumn{2}{|c|}{$1086.3(0.000)$} & \multicolumn{2}{|c|}{$243.9(0.000)$} \\
\hline
\end{tabular}

Exponentiated coefficients reported. Controlling for month of birth and for year fixed effects. Standard errors in parentheses

${ }^{*} p<0.10,{ }^{* *} p<0.05,{ }^{* * *} p<0.01$

In Table 4, we report the analysis in which the data about the macro-areas are pooled together adding controls for the GDP per capita and for the caesarean rate. In particular, columns 1 and 2 report respectively the results for male and female babies. It should be noted that the depressing effect of the 17th day is confirmed also by the pooled analysis. In addition, considering the interaction terms, if we set to one the value of the dummy associated to the 17th day of the month, we have that going from a macro-region where the caesarean rates is low (first quartile) to a macro-region in which the practice is widely diffused (fourth quartile), the incident rate of birth (for both male and female babies) is furtherly reduced. When the category of the ces_rate are considered (without the interaction), we find that when the recourse to the caesarean section increases also the incidence ratio rises, thus indicating a larger discrepancy from a situation of equal distribution among days. The fact that the last category is not significant is very likely due to the fact that the effect is already captured by the dummy associated to Southern Italy. The caesarean rate of this macro-region is indeed clearly higher than those registered in other macro-regions and thus entirely comprised in the fourth category of our variable (see Fig. 3).

\section{Conclusions}

In its recent recommendations to avoid unnecessary caesarean sections, the WHO reported that "Factors associated with caesarean births include changes in the characteristics of the population such as increases in the prevalence of obesity and of multiple pregnancies and increases in the proportion of nulliparous women or of older women. These changes are unlikely, however, to explain the large increases and wide variations in caesarean section rates across countries. Other non-clinical factors such as women increasingly wanting to determine how and when their child is born, generational shifts in work and family responsibilities, physician factors, increasing fear of medical litigation, as well as organizational, economic and social factors have all been implicated in this increase" (WHO, 2018, p. 8).

The concentration of births on working days accompanied by a relative lack of events on weekends or during the public holidays has been interpreted as evidence of an excessive appeal for elective delivery (Lerchl, 2005). In addition to the weekend/holiday 
Table 4 The calendar effect on the daily births pooling macro-regions

\begin{tabular}{|c|c|c|c|c|}
\hline \multirow[t]{2}{*}{ Variables } & \multicolumn{2}{|l|}{$1-M$} & \multicolumn{2}{|l|}{$2-F$} \\
\hline & IRR & S.E. & IRR & S.E. \\
\hline \multicolumn{5}{|l|}{ Day of the month } \\
\hline 1 & $0.979^{* * *}$ & $(0.005)$ & $0.974 * * *$ & $(0.005)$ \\
\hline 2 & $0.989^{* *}$ & $(0.005)$ & $0.986^{* * *}$ & $(0.005)$ \\
\hline 3 & 1.004 & $(0.005)$ & 1.001 & $(0.005)$ \\
\hline 4 & 1.005 & $(0.005)$ & 1.003 & $(0.005)$ \\
\hline 5 & 1.001 & $(0.005)$ & 0.993 & $(0.005)$ \\
\hline 6 & 0.994 & $(0.005)$ & $0.984^{* * *}$ & $(0.005)$ \\
\hline 7 & 0.996 & $(0.005)$ & $0.991^{*}$ & $(0.005)$ \\
\hline 8 & 0.994 & $(0.005)$ & 0.998 & $(0.005)$ \\
\hline 9 & $0.989^{* *}$ & $(0.005)$ & $0.984^{* * *}$ & $(0.005)$ \\
\hline 10 & $0.991^{*}$ & $(0.005)$ & 0.996 & $(0.005)$ \\
\hline 11 & $0.989^{* *}$ & $(0.005)$ & 0.993 & $(0.005)$ \\
\hline 12 & 0.993 & $(0.005)$ & $0.990^{* *}$ & $(0.005)$ \\
\hline 13 & $0.977^{* * *}$ & $(0.005)$ & $0.973^{* * *}$ & $(0.005)$ \\
\hline 14 & $0.985^{* * *}$ & $(0.005)$ & $0.982^{* * *}$ & $(0.005)$ \\
\hline 15 & Ref & & Ref & \\
\hline 16 & $0.991^{*}$ & $(0.005)$ & $0.988^{* *}$ & $(0.005)$ \\
\hline 17 & $0.966^{* * *}$ & $(0.008)$ & $0.962^{* * *}$ & $(0.008)$ \\
\hline 18 & 1.005 & $(0.005)$ & 1.006 & $(0.005)$ \\
\hline 19 & 1.000 & $(0.005)$ & 0.994 & $(0.005)$ \\
\hline 20 & $1.010^{* *}$ & $(0.005)$ & 1.005 & $(0.005)$ \\
\hline 21 & 0.996 & $(0.005)$ & 0.994 & $(0.005)$ \\
\hline 22 & $0.984^{* * *}$ & $(0.005)$ & $0.986^{* * *}$ & $(0.005)$ \\
\hline 23 & 0.993 & $(0.005)$ & $0.990^{*}$ & $(0.005)$ \\
\hline 24 & 1.000 & $(0.005)$ & 1.004 & $(0.005)$ \\
\hline 25 & $0.982^{* * *}$ & $(0.005)$ & $0.979^{* * *}$ & $(0.005)$ \\
\hline 26 & $0.985^{* * *}$ & $(0.005)$ & $0.987^{* *}$ & $(0.005)$ \\
\hline 27 & 1.000 & $(0.005)$ & 0.997 & $(0.005)$ \\
\hline 28 & 0.999 & $(0.005)$ & 0.993 & $(0.005)$ \\
\hline 29 & $0.983^{* * *}$ & $(0.005)$ & $0.974^{* * *}$ & $(0.005)$ \\
\hline 30 & $0.986^{* * *}$ & $(0.005)$ & $0.984^{* * *}$ & $(0.005)$ \\
\hline 31 & $0.985^{* *}$ & $(0.006)$ & $0.974^{* * *}$ & $(0.006)$ \\
\hline \multicolumn{5}{|l|}{ Day of the week } \\
\hline Sunday & $0.692^{* * *}$ & $(0.002)$ & $0.686^{* * *}$ & $(0.002)$ \\
\hline Monday & $0.988^{* * *}$ & $(0.002)$ & $0.985^{* * *}$ & $(0.002)$ \\
\hline Thursday & $1.015^{* * *}$ & $(0.002)$ & $1.013^{* * *}$ & $(0.002)$ \\
\hline Wednesday & Ref & & Ref & \\
\hline Tuesday & $1.043^{* * *}$ & $(0.002)$ & $1.041^{* * *}$ & $(0.003)$ \\
\hline Friday & $0.829^{* * *}$ & $(0.002)$ & $0.823^{* * *}$ & $(0.002)$ \\
\hline Saturday & 1.000 & $(0.002)$ & 1.000 & $(0.002)$ \\
\hline Fri_17 & $0.971^{* * *}$ & $(0.010)$ & $0.968^{* * *}$ & $(0.010)$ \\
\hline End/first of the year & $0.750^{* * *}$ & $(0.008)$ & $0.752^{* * *}$ & $(0.008)$ \\
\hline Civil feast & $0.777^{* * *}$ & $(0.006)$ & $0.777^{* * *}$ & $(0.007)$ \\
\hline
\end{tabular}


Table 4 The calendar effect on the daily births pooling macro-regions (Continued)

\begin{tabular}{|c|c|c|c|c|}
\hline \multirow[t]{2}{*}{ Variables } & \multicolumn{2}{|l|}{$1-M$} & \multicolumn{2}{|l|}{$2-F$} \\
\hline & IRR & S.E. & IRR & S.E. \\
\hline Christmas & $0.746^{* * *}$ & $(0.006)$ & $0.732^{* * *}$ & $(0.006)$ \\
\hline Other rel. feast & $0.770^{* * *}$ & $(0.004)$ & $0.759^{* * *}$ & $(0.005)$ \\
\hline All Souls' day & $0.844^{* * *}$ & $(0.012)$ & $0.836^{* * *}$ & $(0.012)$ \\
\hline GDP & $1.000^{* * *}$ & $(0.000)$ & $1.000^{* * *}$ & $(0.000)$ \\
\hline \multicolumn{5}{|l|}{ Caesarean rate (categorized) } \\
\hline 1st quartile & Ref & & Ref & \\
\hline 2nd quartile & $1.035^{* * *}$ & $(0.003)$ & $1.038^{* * *}$ & $(0.003)$ \\
\hline 3rd quartile & $1.096^{* * *}$ & $(0.005)$ & $1.102^{* * *}$ & $(0.006)$ \\
\hline 4th quartile & 0.994 & $(0.009)$ & 1.001 & $(0.007)$ \\
\hline \multicolumn{5}{|l|}{ Interaction term } \\
\hline 2nd quartile $\times 17$ th day & 1.003 & $(0.010)$ & 0.993 & $(0.010)$ \\
\hline 3rd quartile $\times 17$ th day & $0.967^{* * *}$ & $(0.010)$ & 0.986 & $(0.010)$ \\
\hline 4th quartile $\times 17$ th day & $0.961^{* * *}$ & $(0.009)$ & $0.957^{* * *}$ & $(0.010)$ \\
\hline$N$ & \multicolumn{2}{|l|}{31,045} & \multicolumn{2}{|l|}{31,045} \\
\hline pseudo $R^{2}$ & \multicolumn{2}{|l|}{0.204} & \multicolumn{2}{|l|}{0.203} \\
\hline $\begin{array}{l}\text { Likelihood-ratio test of alpha }=0 \\
\text { (chi- } p \text { value) }\end{array}$ & \multicolumn{2}{|c|}{$7955.6(0.000)$} & \multicolumn{2}{|c|}{$7503.6(0.000)$} \\
\hline
\end{tabular}

Controlling for month of birth, year fixed effects, and macro-region fixed effects. Standard errors in parentheses corrected for cluster for day month combination ${ }^{*} p<0.10,{ }^{* *} p<0.05,{ }^{* * *} p<0.01$

effect already found in other countries, in Italy, superstitions also seem to be included in the list of social factors that play a role in determining the calendar of births. According to Italian popular tradition (see Breschi \& Ruiu, 2016 for a discussion), the number 17 is considered ominous. In this paper, we have shown that the 17th day of the month is indeed one of the days characterised by the lowest number of births, especially in Southern Italy. A similar effect is also exerted by All Souls' Day. We believe that these findings are indicative of a systematic abuse in the practice of elective delivery. In addition to the concerns regarding the consequences on the health of both mothers and babies expressed by the WHO, it must be remarked that this artificialisation of the calendar of births seems to respond, in the best case scenario, to irrational beliefs held by parents, in the worst, to the same irrational beliefs of practitioners who do not want to operate on "unlucky" days.

Finally, we believe that our methodology could be useful to signal potential situation of abuse in the practice of elective delivery.

Acknowledgements

We thank two anonymous referees for their precious comments.

Authors' contributions

All the authors have contributed equally to each section. All authors read and approved the final manuscript.

Funding

The research activity carried out by Gabriele Ruiu has been in part financed by the "Fondo per il finanziamento dei dipartimenti universitari di eccellenza" (Law nr. 232/2016). 
Competing interests

The authors declare that they have no competing interests.

Received: 18 March 2019 Accepted: 5 June 2019

Published online: 21 June 2019

\section{References}

Breschi, M., Gonano, G., \& Ruiu, G. (2018). Le nascite tra la fine e l'inizio dell'anno: dagli artifici del passato al presente artificiale. Popolazione e Storia, 19(1), 85-114.

Breschi, M. \& Ruiu, G. (2016). Superstitions, religiosity and secularization; An analysis of the periodic oscillations of weddings in Italy, Genus Genus, 72(7). https://doi.org/10.1186/s41118-016-0012-0.

Gini, C. (1934). Su la portata e gli effetti delle false denunce di nascita per i nati denunciati al principio dell'anno. Bulletin de I'Institut International de Statistique, 28(2), 3-39.

Gini, C., \& D'Addario, R. (1930). Intorno alla portata delle date di nascita differite per i nati alla fine dell'anno. Annali di Statistica, VI(XVIII)

Gini, C., Naddeo, A., \& Passeggeri, S. (1954). Sulla diffusione del ritardo nella registrazione delle nascite avvenute negli ultimi giorni dell'anno. Extracted by Bollettino dell'Istituto internazionale di Statistica (Vol. 34, p. 3).

Gorard, S. (2007). The dubious benefits of multi-level modelling. International Journal of Research and Method in Education, 30, 221-236.

Hilbe, J. (2011). Negative binomial regression (2nd ed.). Cambridge: Cambridge University Press.

Jones, K., Johnston, R., Manley, D., Owen, D., \& Charlton, C. (2015). Ethnic residential segregation: A multilevel, multigroup, multiscale approach exemplified by London in 2011. Demography, 52, 1995-2019.

Lerchl, A. (2005). Where are the Sunday babies? Observations on a marked decline in weekend births in Germany. Naturwissenschaften, 92, 592-594.

Lerchl, A., \& Reinhard, S. C. (2008). Where are the Sunday babies? II. Declining weekend birth rates in Switzerland. Naturwissenschaften, 95(2), 165-170.

Livi, L. (1929). Sulle false dichiarazioni della data di nascita per i nati alla fine dell'anno, e rettifica della distribuzione mensile delle nascite nel triennio 1923-1925. Annali di Statistica S, VI, V. III, 41-109.

Maroi, L. (1954). La periodicità giornaliera dei nati e dei morti in Italia. Statistica, 14(3), 412-423.

Ministero della salute. (2017). Certificato di assistenza al parto (CeDAP). Analisi dell'evento nascita - Anno 2014. Roma: Direzione Generale della digitalizzazione, del sistema informativo sanitario e della Statistica - Ufficio di Statistica.

Morikawa, M., Yamada, T., Chiba, K., Hosokawa, A., Sato, S., Ishikawa, S., \& Minakami, H. (2016). Perinatal mortality rate in weekend birth in Japan. Critical Care Obstetrics and Gynecology, 2(5.23), 1-5.

Mussino, E., Miranda, V. \& Ma, L. (2018). Changes in sex ratio at birth among immigrant groups in Sweden. Genus. https://doi. org/10.1186/s41118-018-0036-8.

Norton, E. C., Wang, H., \& Ai, C. (2004). Computing interaction effects and standard errors in logit and probit models. Stato Journal, 4(2), 154-167.

Peña, P. A. (2015). A not so happy day after all: Excess death rates on birthdays in the U.S. Social Science and Medicine, 126, 59-66.

Terzera, L. (2002). The evolution of multiple births in Italy. Genus, 58(1),159-181.

WHO. (2015). Statement on caesarean section rates. In Human Reproduction Program (WHO/RHR/15.02).

WHO. (2018). Recommendations: Non-clinical interventions to reduce unnecessary caesarean sections. Geneva: World Health Organization (ISBN:978-92-4-155033-8).

\section{Publisher's Note}

Springer Nature remains neutral with regard to jurisdictional claims in published maps and institutional affiliations.

\section{Submit your manuscript to a SpringerOpen ${ }^{\circ}$ journal and benefit from:}

- Convenient online submission

- Rigorous peer review

- Open access: articles freely available online

High visibility within the field

Retaining the copyright to your article

Submit your next manuscript at $\boldsymbol{\sim}$ springeropen.com 